\title{
Research on the Improvement Strategy of Marketing Talents Training in Secondary Vocational Schools
}

\author{
Fuchang Li, Fengrui Liu, Xiaohui Hu* \\ School of Economics \& Management,Yunnan Normal University \\ Yunnan, China \\ *corresponding author
}

\begin{abstract}
Secondary vocational education is an important part of China's vocational education system. Its core is the cultivation of students' professional ability and professional quality. However, there are many problems in the marketing major of secondary vocational schools in China. For example: talent training target is single; secondary vocational schools have low attention to marketing positions; education and teaching supervision system is not strict; teachers' scale is small and quality thereof is low; teacher have fewer training and improvement opportunities; teaching enthusiasm and teaching quality are low, ect. Based on these issues, this paper analyzes a series of solutions.
\end{abstract}

Keywords-Secondary Vocational Schools; Marketing; Talent development

\section{INTRODUCTION}

Among the vocational education systems in China, secondary vocational education is an important part of it. Secondary vocational education is different from ordinary high school education or higher vocational education. The secondary vocational school marketing specialty is positioned to cultivate practical application talents who meet market needs and corporate requirements, have marketing expertise and skills, have high professionalism and comprehensive ability, and have innovative spirit and learning ability. At present, the teaching mode and teaching structure of the market training of secondary vocational schools are not targeted, and the difference between high school education and higher vocational education is not obvious. The training mode has the characteristics of unclear characteristics, imperfect teaching content and curriculum system. At the same time, the structure of the faculty of marketing in secondary vocational schools is also problematic. The number and quality of teachers cannot meet the teaching needs and lack the teachers with strong academic ability. The teaching methods are relatively simple, the students have less practical training, and the students have weak practical ability to adapt to the rapidly changing economic environment and social environment.

\section{PROBLEMS IN THE TRAINING OF MARKETING PROFESSIONALS IN SECONDARY VOCATIONAL SCHOOLS}

\section{A. School level}

\section{1) Talent training target is single}

The students trained in the marketing of secondary vocational schools should be practical application talents who meet the needs of the market and the requirements of enterprises, have the marketing expertise and skills, have high professionalism and comprehensive ability, and have innovative spirit and learning ability. With the development of social economy, industrial development is becoming more and more demanding, and talents of different levels and levels are required by the society, especially in high-level fields. The demand for high-skilled talents is enduring. However, from the current training process and results of the marketing profession in secondary vocational schools, the talents of the target training are single and low, focusing on small and mediumsized enterprises in the financial sector. The positions are mostly sales managers, and the salary is also at a medium level. To a certain extent, this reflects that the positioning of marketing professionals has not been adjusted in time to meet the needs of the market for continuous updating and upgrading. The changes in the training objectives are floating on the surface, and there is no corresponding adjustment of the training program to meet the needs of the market. Most of the graduates' employment is concentrated in the middle and lowlevel areas, reflecting the single level of training objectives, the pressure of employment is large, the middle and low fields are oversaturated, and the high-skilled areas are extremely scarce. On the other hand, the quality of employment of graduates cannot be improved, which limits the possibility of graduates developing to a deeper level and higher fields.

2) Secondary vocational schools have low attention to marketing positions

The marketing position is the number one position in the job market, and the total demand is large and distributed in various positions in various industries. The conditions and requirements for employees in different positions are not the same. Understand the needs of the post, in order to determine the training objectives and training plans according to their expectations, from the vocational skills, comprehensive quality, qualifications and other aspects of training. However, judging from the current employment situation of graduates of 
marketing majors, the survey of graduates' status and corporate feedback, many graduates are not in a good employment situation. The application phase can't meet the requirements of the enterprise requirements, can't be qualified for most positions, or expose the knowledge reserves and skills in the actual work. In addition to the graduates' own factors, there is a certain relationship with the secondary vocational schools' lack of active and incomplete understanding of market demand. Unclear training objectives and unscientific teaching attitudes will reduce the quality of teaching and thus reduce the overall quality of graduates.

\section{3) Education and teaching supervision system is not strict}

In recent years, in order to cultivate high-skilled and high-quality labor, the state has invested a large amount of funds, manpower and material resources to support the development of vocational education. Vocational and technical education has completed many developments and reforms. Advanced teaching concepts, teaching forms and teaching equipment have entered secondary vocational schools, improving the quality of teaching. However, input and output are not completely proportional, and many advanced concepts, equipment, and methods cannot be implemented. On the one hand, the level of teachers is not enough, the enthusiasm for teaching is not high, and the class is perfunctory; on the other hand, the students' enthusiasm for learning is not high and the learning attitude is not good. Most of the secondary vocational schools' marketing professions are not efficient, students are reluctant to participate and learn, teachers are not allowed to do so, and schools are not strictly controlled. As a result, students are lower in level and teaching quality is poor. Therefore, the lack of strict education and teaching management system is also an important reason for the poor quality of education. Without an effective management system to constrain the evaluation of teachers' teaching quality, students' learning effects, and management of students' performance in school, they will let students develop bad behaviors, resulting in the continuous decline in the quality of education and teaching.

\section{B. Teacher level}

\section{1) Small scale and low-quality teachers}

Teacher strength is an important criterion for measuring the strength of a school. Teachers are the main body of teaching and an important person in charge of personnel training. The quality of teachers determines the quality of education to a certain extent. In the expansion of some schools, the professional teachers are insufficient, and some part-time teachers participate little in teaching. Among the teachers who serve, the number of teachers with senior titles is small, and the opportunities for teachers to enter the company for training are also less. On one hand, insufficient teacher resources will have a certain impact on teaching. Teachers' own experience is insufficient, and insufficient ability will affect students' mastery of knowledge and skills. On the other hand, there is no excellent faculty as a brand attraction, which has a certain degree of influence on the enrollment and employment of marketing professionals.
2) Less training or improvement opportunities for teachers Teachers are an important guarantee for the dissemination of new knowledge and skills in the teaching process. Therefore, the level of teachers determines the level of students' learning. For the profession that is updated in time as the market changes, teachers should update their professional skills and knowledge reserves at any time. In addition to the teachers' own efforts, the opportunities provided by the school are particularly important. Secondary vocational schools should arrange practical training for teachers from multiple channels and multiple frequencies, such as arranging teachers to concentrate on learning, to conduct corporate training, and invite industry experts to arrange teacher training or lectures.

\section{3) Low teaching enthusiasm quality}

Many teachers in secondary vocational schools have problems such as unprofessional teaching, low enthusiasm for class, and inadequate management of students. Teachers have less interaction with students in the classroom and are not very concerned about the quality of teaching. On one hand, students in secondary vocational schools are less self-conscious, and their interest in learning is not very high. Students are reluctant to learn and are not willing to participate in interaction, resulting in teachers not having high enthusiasm. On the other hand, teachers in secondary vocational schools do not have the pressure to go to school, and there are no hard indicators to complete. Therefore, the enthusiasm for teaching is not high. In addition, the teaching supervision is not in place, there is no systematic strict management system to supervise the teaching quality of teachers, lack of motivation and constraints, is also one of the main reasons.

\section{THOUGHTS AND COUNTERMEASURES ON THE REFORM OF MARKETING PROFESSIONAL TALENTS IN SECONDARY VOCATIONAL SCHOOLS}

\section{A. Establish a competitive advantage in schools}

The characteristics of running a school are unique in the long-term schooling process, which is different from other schools' unique school-running styles, unique school-running concepts, and characteristics in personnel training, teaching research, and campus culture. The difference between a secondary vocational school and an undergraduate school is that it cultivates application-oriented talents and creates a "artisan spirit". Its position is to continuously cultivate highquality skilled and applied talents for the society. "Apply" is its distinctive label, and it is also stronger than others' characteristics and advantages. In recent years, in order to promote undergraduate courses, some colleges have moved closer to the undergraduate in all aspects of school-running characteristics, talent orientation, curriculum teaching, and teaching staff. The lack of strength and the quality of teaching are not high, weakening their own advantages and tending to cultivate in weak areas, resulting in graduates who are far less academically qualified than high-quality undergraduate students and cannot compare with undergraduates in applied skills. In order to increase the number of undergraduate students, some colleges and universities encourage all students to go to the college entrance examination, compress practical courses in curriculum arrangement and teaching design, and 
increase the duration of theoretical courses. The characteristic is the competitive advantage of the school. In the process of development and upgrading, the school cannot lose its own advantages.

\section{B. Focus on corporate information feedback and adjust training programs based on feedback}

The supply and demand situation of the talent market, the hot jobs of employment, the hot trend of the industry, and the changes in the demand for talents of enterprises are all obtained through information collection and feedback. From the perspective of marketing, the most urgent talent is the new media Internet marketing talents who can use big data technology. In addition to the continuous updating of the demand for talents, the trends in the fields of industry and jobs are constantly changing. The development of e-commerce has led to an increase in the demand for online sales. The development of emerging industries such as energy will inevitably require a large amount of marketing talents. Therefore, mastering the market trends, taking the lead in adjusting the direction and content of training, starting from the pain point of solving the market and corporate talent demand, and providing high-skilled talents with a driving role for the renewal of enterprises and society is the key to the school's invincibility.

\section{Develop broad employment channels}

For the outside of the school, the secondary vocational school is a subsystem in the whole social system, and its service marketing process will have a relationship and role with the enterprise, the government and the public. At this stage, the employment of graduates in marketing schools in secondary vocational schools is not optimistic. The supply of jobs is less than the demand for jobs. The competition is fierce. Some higher-level jobs have many restrictions on secondary vocational school students. Successful employment in the fierce competition for employment and employment in higher fields depends on the quality of the graduates themselves. On the other hand, the employment channels also play a very important role. School-enterprise cooperation is one of the characteristics of talent training in higher vocational colleges. In the whole process of school-enterprise cooperation, enterprises have greatly helped the cultivation of school talents and promoted the employment of school graduates. Therefore, it is very important to establish a stable and stable cooperative relationship with the company for the training of students in school and the successful employment of graduates. Strengthen the interaction and contact with all aspects of the enterprise. The information exchange between the school and the enterprise, resource sharing, mutual assistance and mutual benefit are both win-win situations for both schools and enterprises.

\section{Create a good brand and optimize students' school development}

School brand refers to a series of strategic decisions, such as positioning, publicity, management, and maintenance, to improve the quality and efficiency of running schools, and thus enhance the visibility and strong value-added of the school. Brand is also the label and advantage of a school. The most important aspect of building a good brand in school is to improve the quality of education. Just as quality is one of the most important criteria for testing the value of goods, the quality of education and teaching plays a decisive role for schools and is the life of the school. One of the primary considerations for students and parents in choosing a school is the quality of education and teaching. When choosing a school graduate, the quality of the graduates is considered. The school is the producer, the enterprise is the buyer. Graduates are the products provided by the school. The quality of graduation is the quality of the products. It represents the quality of the school and is directly related to the creation of the school brand. However, according to the survey data and field research, the quality of the school's education is not high, and many problems are exposed during the training process, such as poor teaching quality, low rate of graduates, low quality of employment, and graduates in employment. In particular, the problems that graduates appear in actual positions directly affect the continuity of cooperation between schools and enterprises. These problems will not be solved by corresponding measures. They will only become more and more serious, affecting the good brand of the school, and will have an adverse impact on the enrollment of students and the employment of graduates. Therefore, it is necessary to optimize the school-based training, starting from the three levels of school, teachers and students, paying attention to the completion of each link such as teaching goal setting, curriculum setting, teaching quality management, student learning quality supervision, and internship training. Starting from the whole process of school training, grasp every link in education and teaching, paying special attention to the quality of teaching and training, so that advanced concepts can be truly translated into practice and achievements. Only when the quality of education is improved, the quality of students, ability, and rate of enrollment are improved, the reputation of the school will be better, and a good brand can be established.

\section{ACKNOWLEDGEMENTS}

The authors greatly appreciate the anonymous referees and the associate editor for their very valuable and helpful suggestions on an earlier version of the paper. This research is supported by the NSF of China (Grant No. 71562036),Project on Applied Basic Research in Yunnan province (2015FB142), Youth Leaders Project in Academic and Technical of Yunnan Province (2014HB009), and Yunnan provincial doctoral discipline construction planning (Applied Economics). 


\section{REFERENCES}

[1] Shubo Tian. Marketing Talent Training Mode Based on Schoolenterprise Cooperation [J]. Education and Occupation. 2012,(10):118119.

[2] Xiaolan Sheng. Study on Talent Cultivation Model of Marketing Specialty of Higher Vocational Education Based on Economic Transformation Background in Suzhou[J].Vocational and Technical Education. 2010,(32):20-23.

[3] Juan Tan. Guijie Long. Research on Project-based Teaching Model Based on Marketing Applied Talents Training[J]. Academic Forum. 2015,(4):177-180.

[4] Qiangxin Huang. Analysis on the Talent Training Mode of "Double Subject Customization" in the Marketing Major of Secondary Vocational Schools[J]. Chinese Vocational and Technical Education. 2018,(7):93-96. 